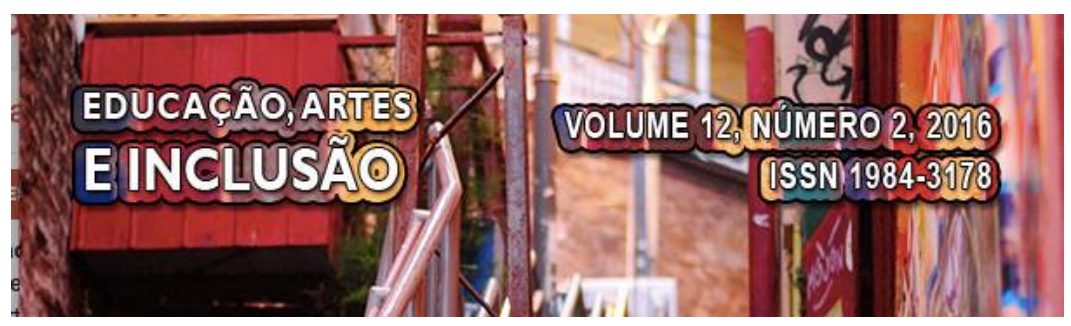

\title{
POSSIBILIDADES E INTERVENÇÕES NO BRINCAR DA CRIANÇA COM DEFICIÊNCIA VISUAL
}

\author{
POSSIBILITIES AND INTERVENTION IN CHILD PLAY WITH \\ VISUAL IMPAIRMENT
}

DOI: $\underline{\text { http://dx.doi.org/10.5965/1984317812022016100 }}$

Ivan Vale de Sousa - UNIFESSPA

\begin{abstract}
RESUMO
A ludicidade na perspectiva da criança com deficiência visual abrange uma significância no processo de formação infantil. Nesse sentido, este trabalho de natureza bibliográfico-reflexivo, objetiva destacar a relevância de atividades lúdicas, tendo como público, as crianças com deficiência visual, discutir sobre a função das intervenções de pais e profissionais no brincar infantil, refletir sobre o processo de interação e do jogo do faz de conta e, por fim, sugerir a revisitação das cantigas de rodas no âmbito de formação e experiência da criança. Para isso, os apontamentos reflexivos transitarão entre as contribuições de autores, tais como: Negrine (1994), Kishimoto (1999), Bondía (2002), Siaulys (2007), Marangon (2011), entre outras reflexões que serão pontuadas ao longo deste artigo. Assim, espera-se que os apontamentos elucidados nesta produção permitam repensar a oferta e a acessibilidade no brincar infantil envolvendo as crianças com deficiência visual.
\end{abstract}

Palavras-chave: ludicidade, crianças com deficiência visual, cantigas de roda.

\begin{abstract}
The playfulness in the child's perspective with visual impairment covers a significance in the child education process. In this sense, this work of literature-reflective nature, aims to highlight the importance of recreational activities, with the public, children with visual impairment, discuss the role of interventions to parents and professionals in children's play, reflect on the process of interaction and Any game account and finally suggest the revisiting of wheels songs within the training and experience of the child. To this end, the reflective notes carried over from the contributions of authors, such as Negrine (1994), Kishimoto (1999), Bondía (2002), Siaulys (2007), Marangon (2011), among other considerations that will be scored along this article. Thus, it is expected that the notes elucidated in this production allow rethink the supply and accessibility of children's play involving children with visual impairment.
\end{abstract}

Keywords: playfulness, visually impaired children, nursery rhymes.

\section{INTRODUÇÃO}

Sabemos que as relações sociais permitem à criança o aprendizado, a construção e a ampliação de conhecimentos. Essas vivências admitem a descoberta e a redescoberta das 


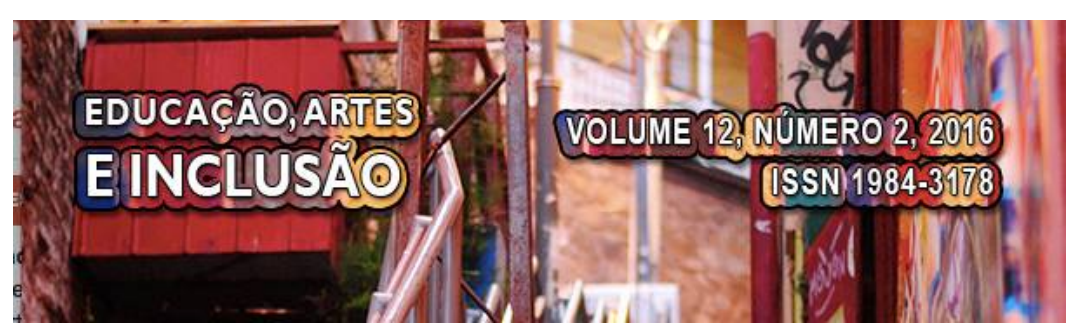

da criança. É comum e, ao mesmo tempo, perceptível que em algumas brincadeiras há a imitação dos adultos por parte dos pequenos, visto que, estes os enxerga como referências ou modelos a serem seguidos.

\begin{abstract}
Nisso se baseia toda a importância da aprendizagem para o desenvolvimento, e é isto o que constitui o conteúdo do conceito de zona de desenvolvimento imediato. A imitação, se concebida em sentido amplo, é a forma principal em que se realiza a influência da aprendizagem sobre o desenvolvimento. A aprendizagem da fala, a aprendizagem na escola se organiza amplamente com base na imitação. Porque na escola a criança não aprende o que sabe fazer sozinha, mas o que ainda não sabe e lhe vem a ser acessível em colaboração com o professor e sob a sua orientação. (VYGOTSKI, 2001, p. 331)
\end{abstract}

As descobertas para as crianças se efetivam a partir dos momentos de brincadeiras que lhes são oportunizados. Há, nesse sentido, a construção da identidade infantil, por isso, a importância de ambientes estimuladores, bem como, a figura dos pais torna-se relevante. É preciso oferecer a oportunidade de explorar e descobrir o conhecimento por si mesmas, pois, o brincar na concepção da criança vai muito além de apenas passar o tempo.

Explorar o ambiente na perspectiva das crianças significa permitir o aprendizado a partir da manipulação de alguns brinquedos, do incentivo na tomada de decisões e posicionamentos que ocorrem naturalmente entre elas. Tanto as brincadeiras quanto as visualidades dos brinquedos as estimulam para criarem suas convicções sobre o brincar.

É nesse sentido, que é imprescindível repensar o brincar para a criança com deficiência visual, a partir da sugestão de alguns questionamentos é preciso refletir sobre as possibilidades e as intervenções nas brincadeiras da criança em pauta. Isso nos permite refletirmos com base em algumas indagações, como: de que maneira são pensados os momentos de interação e brincadeira para essas crianças? Há um processo de interação com outras ou apenas elas brincam sozinhas? Como elas se apropriam dos benefícios proporcionados pela ludicidade? Quais são os significados que as brincadeiras atribuem à formação da criança com deficiência visual? Como possibilitar-lhe esse acesso? Como têm acontecido os momentos das brincadeiras? Em quais momentos são permitidas as intervenções de um adulto? Qual a importância de interação com outras crianças que não apresentem limitação visual? Assim, os procedimentos metodológicos para averiguação das 


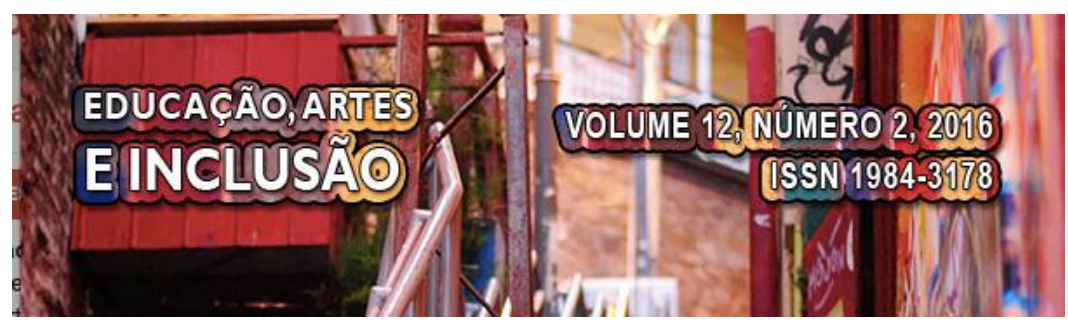

respostas a esses questionamentos dar-se-ão por meio da observação atenta, da intervenção e, ao mesmo tempo, de interação com a criança.

A partir dos questionamentos supracitados, há a necessidade de reflexão, de reavaliação e, principalmente, do repensar de alguns conceitos sobre o brincar nessa perspectiva. É preciso vencer os estereótipos criados socialmente e possibilitar ações que permitem a elas as mesmas chances de interação das crianças sem deficiência visual. Entretanto, faz-se necessário o processo de adaptação destinado a cada especificidade.

A brincadeira é a vida criança e uma forma gostosa para ela movimentar-se e ser independente. Brincando, a criança desenvolve os sentidos, adquire habilidades para usar as mãos e o corpo, reconhece objetos e suas características, textura, forma, cor e som. Brincando, a criança entra em contato com o ambiente, relaciona-se com o outro, desenvolve o físico, a mente, a autoestima, a afetividade, torna-se ativa e curiosa. (SIAULYS, 2005, p. 10)

A ludicidade é inerente às crianças e por isso representa uma das formas de descobrir aos poucos o mundo, quer por meio de suas criações, quer por meio de seus desafios. Daí a necessidade de promover momentos lúdicos, visto que a partir desse contato não se efetiva apenas o brincar, mas o desenvolvimento e a formulação de conceitos.

Antes de oferecer as condições que projetem tanto a aprendizagem quanto ao entretenimento na concepção da criança com deficiência visual é necessário que no contexto escolar o professor planeje e readapte suas intervenções, bem como busque compreender que além da limitação visual apresentado pela criança, outros comprometimentos podem também se fazer presentes. A compreensão, nesse sentido, tem como ponto de partida perceber como ela se apropria, explora, interage, constrói e desconstrói conceitos para o ponto de chegada de como devem ser realizadas as intervenções que potencializem o brincar nesse propósito. Assim, o entendimento de como a criança invisual se apropria e, por conseguinte,

[...] desenvolve um modo particular de ver as coisas ao redor, de explorar, de conhecer o entorno. Ela aprende a interagir com as pessoas e objetos a sua maneira, usando os sentidos remanescentes para perceber, organizar, compreender e conhecer. Portanto, a criança, desde cedo, deve ser estimulada a agir em seu ambiente, a interagir, a conhecer, a saber, e desenvolver-se como toda criança. (DOMINGUES; CARVALHO; ARRUDA 2010, p. 8-9, grifos nossos) 


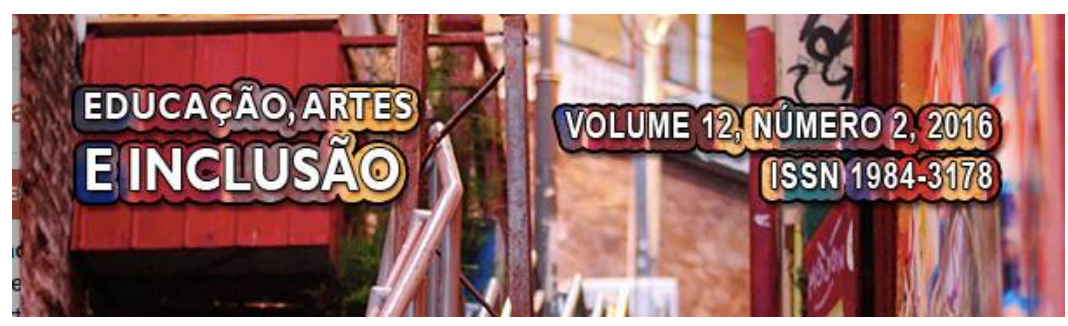

O principal desafio que subjaz à possibilidade do brincar à criança com deficiência visual está em descobrir como ela se apropria e desenvolve habilidades que acontece por meio de um processo de formação e observação desse sujeito. Permitir a ludicidade para as crianças com deficiência visual é entender esse processo como algo contínuo, pois não há uma receita pronta e infalível, visto que cada caso apresenta suas peculiaridades, assim, é necessário partir do contexto em que estão inseridos e aos poucos, oferecer-lhes outras possibilidades.

Partir do contexto, nesse sentido, significa compreender qual a incidência da criança para que se possam planejar as intervenções. Diante disso, é possível compreender que a baixa visão ou visão subnormal é uma condição visual que demanda o uso de táticas e de "recursos específicos, sendo muito importante compreender as implicações pedagógicas dessa condição visual e usar os recursos de acessibilidade adequados no sentido de favorecer uma melhor qualidade de ensino na escola" (DOMINGUES; CARVALHO; ARRUDA, 2010, p. 8).

Muitas são as crenças e os estereótipos que se criam em torno da incidência visual cegueira. Não há, nesse sentido, um poder sobrenatural de perceber, tentar adivinhar as coisas ou senti-las. O que existe é que na ausência da visão, a criança invisual desenvolve os demais sentidos perceptuais e a cegueira, nessa perspectiva, nem sempre significa a ausência de luz como muitos acreditam, pois há casos de pessoas consideradas cegas clinicamente, mas que mesmo assim ainda conseguem perceber por meio de vultos alguns objetivos, mas isso é muito específico de cada caso, conforme a minha experiência de atuação e literaturas específicas na área.

Assim, é possível afirmar que nenhuma pessoa está livre de ser acometida pela cegueira, visto que ela poderá se manifestar em todas as etapas da vida. Entretanto, há diferenças entre a cegueira congênita e a adventícia, conforme podemos entendê-las no excerto a seguir.

A ausência da visão manifestada durante os primeiros anos de vida é
considerada cegueira congênita, enquanto a perda da visão de forma
imprevista ou repentina é conhecida como cegueira adquirida ou
adventícia, geralmente ocasionada por causas orgânicas ou acidentais. (SÁ;
SIMÃO, 2010, p. 30, grifos nossos)

As incidências visuais em hipótese alguma podem ser compreendidas como incapacidade da criança de interagir por meio de jogos infantis e das brincadeiras que lhes são oportunizadas. É por meio das brincadeiras que a criança cria e recria momentaneamente a 


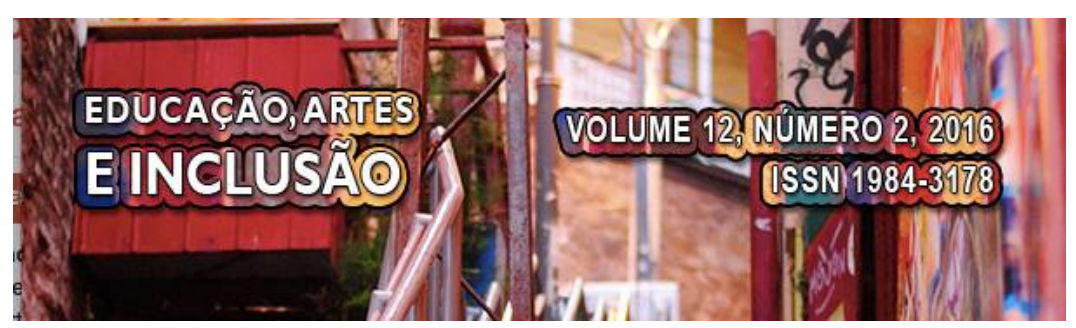

própria vivência. E esses momentos para as invisuais dependerão quase sempre das intervenções que sejam capazes de lhe provocar e auxiliar na apropriação da linguagem por meio da manipulação de objetos, formulando conceitos e contribuindo na tomada de decisões.

Desse modo, para uma criança que não apresenta limitação visual, as cores e os apelos visuais por si sós conseguem aguçar a curiosidade em explorar o objeto (brinquedo). Já para a invisual é necessário, muitas vezes, ensiná-la a brincar, a explorar o ambiente a sua volta, a compreender a partir dos estímulos o que está sendo apresentado e um dos recursos que poderá ser utilizado com esse propósito é a técnica da audiodescrição, isto é, explicações verbais o que significa dar formas e textualizar as palavras.

Assim sendo, na concepção da criança com deficiência visual, o brincar é sinônimo de aprendizado, de descobertas, de construção e ampliação do conhecimento, como também da praticidade de valores éticos como, a solidariedade, o companheirismo e, por conseguinte, das amizades provenientes da interação social.

Ainda assim, o contato com objetos (brinquedos), com o ambiente e com outras crianças de mesma idade permite que a capacidade criadora da criança com deficiência visual seja estimulada, além de lhe permitir que novos conceitos se construam. E por entender que a interação é uma necessidade que há no simples fato de brincar, mas de grande significado para as crianças que a "inteligência, a afetividade, a motricidade e a sociabilidade são inseparáveis, sendo a afetividade a que constitui a energia necessária para a progressão psíquica, moral, intelectual e motriz da criança" (NEGRINE, 1994, p. 19).

Compreender como a criança com deficiência visual se apropria da linguagem e constrói seu mundo simbólico, pressupõe-se refletir acerca das maneiras de interação que estão sendo permitidas à criança, bem como inseri-la nos contextos de aprendizagem específicos não é apenas função da instituição escolar ou das ações docentes, mas compete também à família elucidar esses momentos de ampliação do conhecimento.

Nessa perspectiva social, a importância da família é necessária, visto que o trabalho de ensino-aprendizagem é uma ação que se realize por meio da parceria. Corroborando com a discussão Siaulys (2007) assegura e reconhece que a família é uma entidade que possui características próprias, regras, papéis, símbolos, valores, vinculação emocional intensa, 


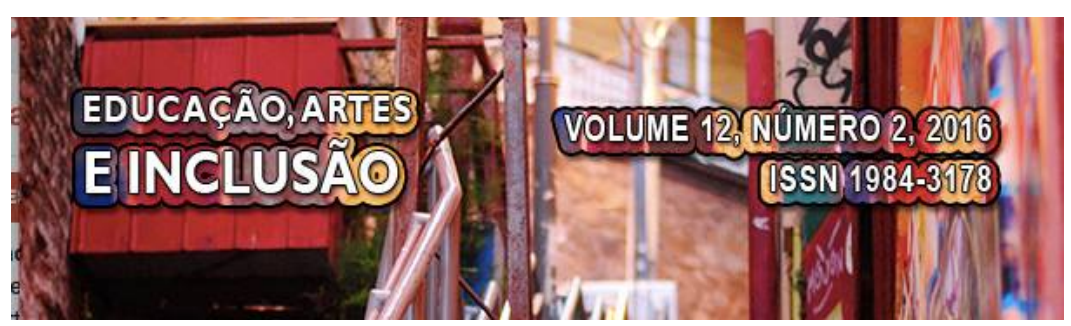

durável e recíproca, com dinâmica particular, padrões específicos de comunicação e estilo típico para a resolução de problemas e tomada de decisões.

É preciso que a família se envolva na aprendizagem dos filhos e compreenda que o brincar para a criança em questão não representa apenas entretenimento, mas uma maneira de construir saberes, de encontro que se dá entre a fantasia e a realidade. Por isso, ela deve ser incluída em todas as brincadeiras, levando-se em consideração as adaptações pertinentes. Nesse sentido, tanto os laços familiares, quanto o respeito e a confiança são trabalhados por mais simplórias que sejam as intervenções, o que enaltecem e enriquecem as experiências.

As proposições efetivadas tanto no contexto escolar quanto na interação entre os familiares e a criança com deficiência visual permitem que a vivência e as descobertas na infância sejam valorizadas e enriquecidas.

\begin{abstract}
As atividades lúdicas permitem que os educadores descubram as capacidades intelectuais, motoras, as potencialidades, habilidades e limitações dos educandos, quando compreendem a sua importância para a aprendizagem e para o desenvolvimento. A diversão, o jogo e a brincadeira potencializam a descoberta, o convívio e a interação, o compartilhamento e a formação de conceitos de forma mais interessante e prazerosa. (SÁ; SIMÃO, 2010, p. 34)
\end{abstract}

Visto que a brincadeira potencializa as descobertas, compete tanto à escola quanto à família oferecer as condições favoráveis de interação na formação da criança com deficiência visual. E toda criança, nesse sentido, necessita vivenciar a partir da diversão e do jogo a formação de novos conceitos, por isso, precisam-se oferecer referências que direcionem à experimentação por meio da ludicidade.

Assim, é preciso compreender que tanto a criança com deficiência visual quanto a que enxerga necessita de direcionamentos e referências e que ambos devem ter as mesmas possibilidades de interação por meio da ludicidade, uma vez que sempre será necessária a adaptação de algumas propostas. Entende-se, pois, brincar na concepção de uma criança com limitação visual é acreditar que ela aprende, conhece, inclui-se e participa das interações sociais ativamente.

\title{
3 INVISUALIDADES ENTRE JOGOS, BRINQUEDOS E BRINCADEIRAS
}




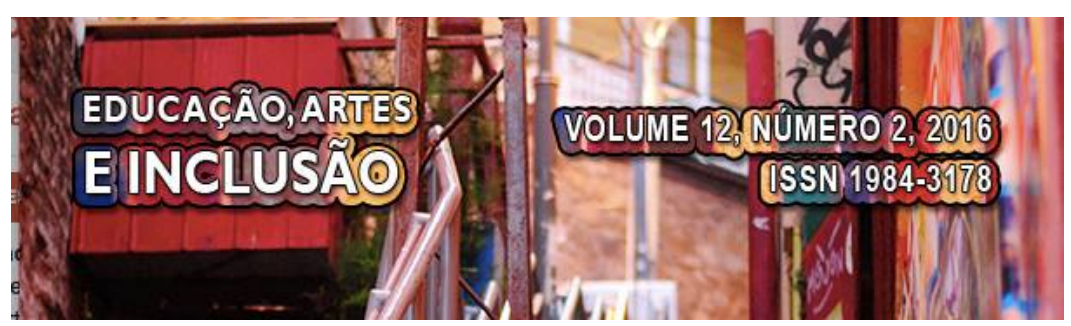

O jogo, o brinquedo e a brincadeira são recursos lúdicos. Por meio desses elementos a criança desenvolve a imaginação e, consequentemente, potencializa a fantasia e a realização do faz de conta efetivada na ação do brincar. E compreender como tais elementos potencializam as habilidades e a construção da linguagem e constituem uma das funções de proposição de experiências.

A diversão na perspectiva da criança com deficiência visual se amplia a partir da organização de espaços estimulantes e enriquecedores com texturas, formas e cheiros que objetivem a ampliação das formas por meio das brincadeiras, direcioná-la também à produção e formulação de conhecimentos, além disso, permite a experimentação, as descobertas e o contato com outras pessoas, principalmente com as que dispõem da visão como via de conhecimento.

O contato com companheiros que enxergam é saudável para todos. Os brinquedos não devem ser vistos como situação de risco ou de perigo. A criança com cegueira deve aprender a lidar com riscos e limites reais e não imaginários, bem como aprender a lidar com a própria limitação. Não há porque ignorar ou negar a falta de visão. Ela aprenderá a identificar sons, ruídos, odores e outras pistas que possibilitem localizar obstáculos e evitar o perigo. (SÁ; SIMÃO, 2010, p. 34)

A realização das brincadeiras na concepção das crianças com deficiência visual não pode ser possibilitada de qualquer forma, antes, exige um planejamento que objetive potencializar o envolvimento de suas aprendizagens. E refletir, nesse sentido, acerca da criação de um projeto que revisite as brincadeiras de outrora, como por exemplo, das cantigas de rodas significa repensar as intervenções que a oriente na manipulação de brinquedos e na valorização do saber que se constrói na coletividade.

O coletivo subentende-se, nessa perspectiva, as cirandas e as cantigas de roda, por isso, a importância da intervenção de um profissional, pois algumas delas exigem a realização de coreografias. Assim, é necessário intervir e ao mesmo tempo orientar na execução dos movimentos, daí a importância de projetar os momentos de recriação.

Toda brincadeira tem seu propósito e, por isso, não deve ser concebida como um passatempo, porque, por meio da brincadeira, a criança sempre coloca em jogo tudo o que sabe. Ocorre, no entanto, que as atividades lúdicas não são tão valorizadas pelos pais e pelos educadores quando se trata de crianças com cegueira. Muitas vezes, em casa e na escola, estas crianças brincam sozinhas ou apenas com adultos que exageram em cuidados e restrições com receio de que elas possam cair ou se machucar. (SÁ; SIMÃO, 2010, p. 34) 


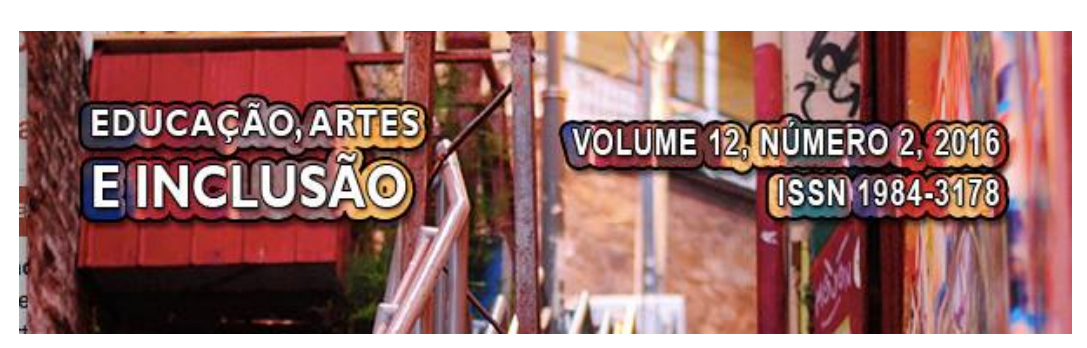

intervenção deliberada no lazer infantil no sentido de oferecer conteúdo pedagógico ao entretenimento da criança. (OLIVEIRA 1984 apud BUENO, 2010, p. 25)

Ao manusear e apropriar-se do brinquedo como recurso destinado à fantasia e à criatividade, a criança invisual constrói seu mundo simbólico a partir da inter-relação com o objeto, uma aproximação e um bem-querer. Assim sendo, tanto o contato quanto o manuseio são capazes de oportunizar o desenvolvimento cognitivo, bem como aguçar a curiosidade na exploração das funcionalidades e especificidades do brinquedo a ser explorado. Entretanto, a aprendizagem intermediada pelo uso de brinquedos é, muitas vezes, não compreendida pelos adultos, que os explora à sua maneira. Mas o que de fato lhe permite explorá-lo? Por que o “danifica”? Quais são os motivos que a leva a agir desse modo?

Um dos principais motivos que permite e aguça a curiosidade da criança em tratar o brinquedo dessa maneira se resume em tentar compreender sobre sua funcionalidade, pois, o ato de desmontar e tentar por inúmeras vezes remontá-lo demonstra a ampla tentativa em compreender o brinquedo parte por parte. Conforme a minha vivência e observação na realização de trabalho com crianças cegas essas ações lhes são comuns. A exploração para as com deficiência visual também não se diferencia: desconstruir é ao mesmo tempo construir, é um desdiz que se afirma no fazer, no experimentar/ vivenciar.

E os brinquedos, nessa concepção, não precisam ser unicamente os comerciais, mas é preferível que haja espaço também para o manuseio e a exploração de brinquedos artesanais, construídos em oficinas entre pais, professores, profissionais e criança, além dos produzidos também pela própria criança, pois a partir de momentos assim, há o respeito e a conservação pelas culturas inerentes ao contexto no qual a criança está inserida.

E por fim, a diversão pode ser efetivada com ou sem a utilização de brinquedos, por isso a importância de potencializar as brincadeiras as quais são essenciais, sobretudo, à interação da criança com limitação visual. Essas atividades, geralmente, apresentam uma sequência musical, seguida de coreografias, como é o caso das cantigas de roda ou das cirandas.

As cantigas de roda precisam ser mais valorizadas na contemporaneidade e de acordo com algumas regiões, assumem características próprias, permitem que sejam conhecidos alguns costumes de determinados povos. Diante disso, a criança com deficiência visual por 


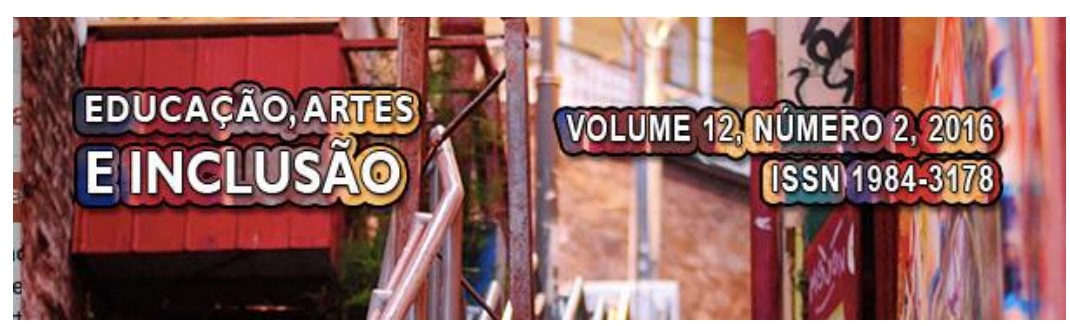

meio das cantigas de roda ou das chamadas cirandas se oportuniza de novas formas de aprender, além de interagir com outras crianças, propicia o trabalho como valores éticos, bem como o respeito pelas diferenças e, nesse sentido, por meio das brincadeiras as crianças exercitam

[...] capacidades nascentes, como as de representar o mundo e de distinguir entre pessoas, possibilitadas especialmente pelos jogos de faz de conta e os de alternância respectivamente. Ao brincar, a criança passa a compreender as características dos objetos, seu funcionamento, os elementos da natureza e os acontecimentos sociais. (OLIVEIRA, 2008, p. 160)

As brincadeiras para o desenvolvimento infantil são essenciais, visto que permitem às crianças adentrarem em um mundo criado por elas mesmas, principalmente, por meio do faz de conta. E no trabalho com a criança com limitação visual a ação de brincar ultrapassa a simplória função de simplesmente entretê-la, representa uma das formas de conhecer as pessoas a sua volta, de reconhecimento do ambiente e de aprendizagem por meio da interação com outras pessoas. Diante disso, as brincadeiras são entendidas como mecanismos educativos e sistematizados, exigindo posicionamento dos participantes.

A fascinação das crianças pelas brincadeiras é inerente às descobertas, por isso que a ação de brincar não é solitária, mas uma representatividade da solidariedade. A criança com deficiência visual interage com as outras a partir da utilização dos sentidos perceptuais (tato, audição, olfato, paladar) e, mesmo em tempos pós-modernos é necessário ensinar e revisitar algumas brincadeiras e oferecê-las, principalmente, as cantigas de roda.

Ainda de maneira tímida, as Instituições de Educação Infantil cumprem a missão possibilitar a interação por meio das canções de roda no processo de socialização. Tais cantigas são metodologias de aprendizagem, desenvolvendo o lado artístico da criança, sobretudo, a com deficiência visual. É preciso, pois, incentivar e permitir que se utilizem as canções infantis no desenvolvimento infantil.

Mais que passatempos, as brincadeiras de roda desenvolvem a expressão oral, a audição e o ritmo dos pequenos. Enquanto rodam no pátio, cantando divertidas canções, eles ainda se exercitam, trabalhando o equilíbrio e a coordenação motora. É importante que os alunos conheçam a coreografia tradicional das cirandas como forma de preservar nossa cultura. Mas incentive as adaptações e a criação de movimentos. (MARANGON, 2011, p. 29, grifos nossos) 


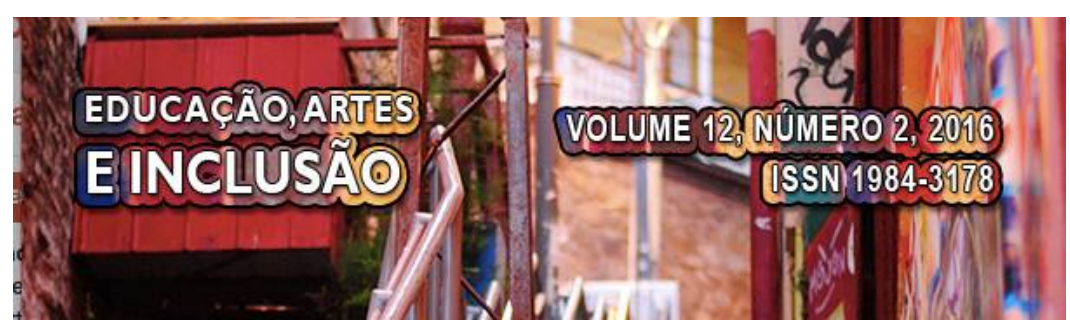

A importância das cantigas de roda se mostra a partir das vivências das crianças com deficiência visual com as demais que não apresentam necessidades educacionais especiais. Nessa perspectiva, objetivando demonstrar a relevância e a revisitação às cantigas de roda será apresentada a seguir canções com sugestões de desenvolvimento e que podem ser utilizadas no contexto da educação da criança.

Objetivando trabalhar com a expressão corporal, o cognitivo e a interação da criança, as sugestões de cantigas de roda podem ser ampliadas de acordo com as necessidades da turma ou das propostas educativas. As canções infantis representam uma das muitas possibilidades de atividades lúdicas na perspectiva da pedagogia do envolvimento e da inclusão. Dessa forma, as sugestões apresentadas no quadro a seguir surgem da experiência prática e por compreender que são necessárias e que podem ser utilizadas como forma de interação entre as crianças. As cantigas de roda foram retiradas da Revista do Professor: Nova Escola - edição especial. Já as propostas de como trabalhá-las são de autorias do autor deste trabalho, o que não impossibilita que outros autores as readapte de acordo com as necessidades das crianças atendidas.

\begin{tabular}{|c|c|}
\hline CIRANDAS & SUGESTÕES \\
\hline $\begin{array}{l}\text { A canoa virou } \\
\text { A canoa virou, } \\
\text { Por deixá-la virar, } \\
\text { Foi por causa do Pedrinho } \\
\text { Que não soube remar. } \\
\text { Se eu fosse um peixinho } \\
\text { E soubesse nadar, } \\
\text { Tirava o Pedrinho } \\
\text { Do fundo do mar. }\end{array}$ & $\begin{array}{l}\text { Esta atividade, o professor poderá organizar no formato de rodas ou } \\
\text { em fileiras. Sugere-se, portanto, a organização de duas filas, nas } \\
\text { quais, cada criança segura no ombro da próxima, fazendo } \\
\text { movimento para a direita e esquerda. Para a criança invisual, essa } \\
\text { atividade desenvolve a confiança, trabalha a memória por meio da } \\
\text { letra da canção, como também possibilita a aprendizagem dos } \\
\text { nomes dos colegas, fortalece os laços de amizade, o respeito mútuo } \\
\text { e a confiança. }\end{array}$ \\
\hline $\begin{array}{l}\quad \text { De abóbora faz melão } \\
\text { De abóbora faz melão, } \\
\text { De melão faz melancia. (bis) } \\
\text { Faz doce, sinhá, faz doce, sinhá. } \\
\text { Faz doce de maracujá. } \\
\text { Quem quiser aprender a dançar } \\
\text { Vai à casa de seu Juquinha. (bis) } \\
\text { Ele pula, ele roda, } \\
\text { Ele faz requebradinho. (bis) }\end{array}$ & $\begin{array}{l}\text { De mãos dadas e em círculo, as crianças começam a girar e } \\
\text { conforme o comando destacado na canção realiza a coreografia. } \\
\text { Esta atividade para a criança invisual desenvolve a linguagem } \\
\text { corporal, a memória e a percepção por meio da cinestesia. Sugere-se } \\
\text { que o proponente acrescente nomes de frutas conhecidas pelas } \\
\text { crianças ou de seu contexto, assim atribui funcionalidade à canção e } \\
\text { à abordagem do campo linguístico infantil. }\end{array}$ \\
\hline $\begin{array}{l}\text { Terezinha de Jesus } \\
\text { Terezinha de Jesus, } \\
\text { De uma queda, } \\
\text { Foi ao chão. } \\
\text { Acudiram três cavaleiros, } \\
\text { Todos os três de chapéu na mão. }\end{array}$ & $\begin{array}{l}\text { A interação se realiza por meio de um círculo, com as crianças de } \\
\text { mãos dadas. O proponente terá a oportunidade de trabalhar com a } \\
\text { ideia de ordenamento, contribuindo com interdisciplinaridade para } \\
\text { as aulas de matemática. Por meio desta canção, sugere-se que haja o } \\
\text { trabalho com a afetividade, conhecendo às pessoas da família, além } \\
\text { disso, desenvolve a expressão corporal, a vocal, a memória e a }\end{array}$ \\
\hline
\end{tabular}




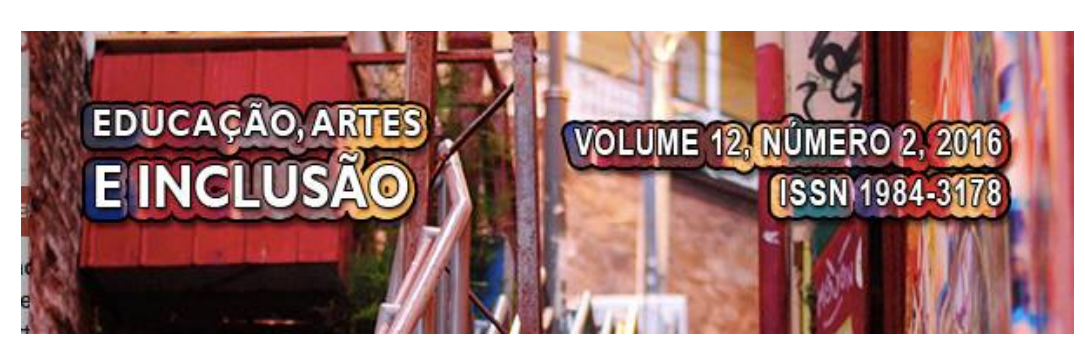

\begin{tabular}{|l|l|}
\hline $\begin{array}{l}\text { O primeiro foi seu pai, } \\
\text { O segundo, seu irmão, } \\
\text { O terceiro foi aquele } \\
\text { Que a Tereza deu a mão. }\end{array}$ & confiança entre os participantes do grupo. \\
\hline \multicolumn{1}{|c|}{ Marcha soldado } & $\begin{array}{l}\text { Esta atividade desenvolve a linguagem e a expressão corporal, além } \\
\text { disso, trabalha com a competitividade de maneira saudável. Sugere- } \\
\text { Marcha, soldado, a formação de duas filas para a efetivação da canção-atividade, } \\
\text { Cabeça de papel! } \\
\begin{array}{l}\text { Quem não marchar direito } \\
\text { Vai preso para o quartel. }\end{array}\end{array}$ \\
$\begin{array}{l}\text { competitividade entre as crianças de forma saudável e a canção } \\
\text { poderá ser cantada em ritmos diferentes que determinarão a marcha } \\
\text { dos 'soldados' e à coordenação dos movimentos. }\end{array}$ \\
\hline
\end{tabular}

Quadro 1 - As cantigas de roda na perspectiva da inclusão. Fonte: Civita (2011)

As cirandas supracitadas cumprem a função de desenvolver a fala, a expressão corporal e o respeito pelo espaço do outro. Além das sugestões elucidadas, outras poderão ser utilizadas considerando o contexto no qual a comunidade discente está inserida. Ressalta-se, ainda, que o professor pode ampliar as intervenções de modo que elas se adaptem às necessidades de aprendizagem e de interação dos sujeitos envolvidos, pois, o objetivo norteador da efetivação das cantigas de roda com crianças que apresentem ou não alguma deficiência é permitir a participação e o compartilhamento desses momentos com todas.

Embora algumas das cantigas de roda se configurem como canções tradicionais todas as crianças precisam conhecê-las e explorá-las. O conhecimento, nesse sentido, com a criança deficiência visual pressupõe descortinar saberes e construir novas formas de conhecimento, assim, nessas atividades, o corpo é a principal via de experimentação por meio dessas vivências.

Assim sendo, conforme a vivência e a atuação com as crianças com deficiência visual, conclui-se que na concepção delas, as brincadeiras são sinônimas de interação e interagir, nessa concepção, pressupõe a experimentação e a ampliação do léxico. A ludicidade na promoção do envolvimento de todas as crianças potencializa a utilização dos sentidos perceptuais de modo a desenvolver a memória, a atenção, a imaginação, a linguagem e, por conseguinte, fortalece o convívio social.

E possibilitar que a criança com limitação visual se aproprie sobremaneira do brincar, é necessário que pais e professores permitam tais momentos. Assim, a relevância das brincadeiras tanto no contexto escolar quanto na família deve ser compreendida a partir de diferentes concepções, conforme apresentadas, a seguir. 


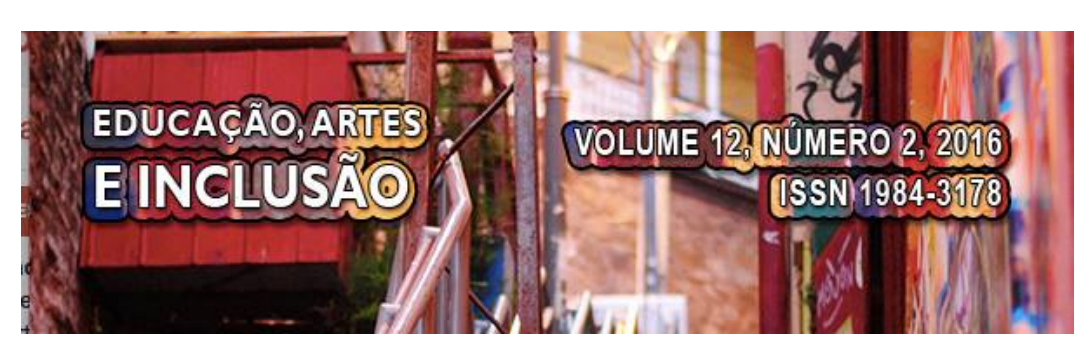

\begin{tabular}{|c|c|}
\hline Filosófico & $\begin{array}{c}\text { É abordado como mecanismo para contrapor à racionalidade. A emoção deverá estar junto } \\
\text { na ação humana tanto quanto a razão. }\end{array}$ \\
\hline Sociológico & $\begin{array}{r}\text { Tem sido visto como a forma mais pura de inserção da criança na sociedade. Brincando, a } \\
\text { criança vai assimilando crenças, costumes, regras, leis e hábitos do meio em que vive. }\end{array}$ \\
\hline Psicológico & $\begin{array}{c}\text { Está presente em todo o desenvolvimento da criança nas diferentes formas de modificação } \\
\text { de seu comportamento. }\end{array}$ \\
\hline Criatividade & $\begin{array}{c}\text { Tanto no ato de brincar como o ato criativo, estão centradas na busca do "eu". É no brincar } \\
\text { que se pode ser criativo, e é no criar que se brinca com as imagens e signos fazendo uso do } \\
\text { próprio potencial. }\end{array}$ \\
\hline Pedagógico & Tem-se revelado como uma estratégia poderosa para a criança aprender. \\
\hline \multicolumn{2}{|c|}{ Quadro 2 - Diferentes concepções relacionadas ao brincar. Fonte: Adaptado de Santos (1999) }
\end{tabular}

As diversas abordagens supracitadas nos permitem repensar sobre a importância do brincar, sobretudo, no contexto da educação inclusiva, pois todas as crianças precisam ter as mesmas oportunidades de desenvolvimento e de interação. Embora nas reflexões de Santos (1999) não se mencione o contexto da inclusão, faz-se necessário, ampliar as discussões e, principalmente, as ações no acolhimento e na permissão de que todos devem ter as mesmas chances.

$\mathrm{O}$ assessoramento durante o faz de conta e o brincar infantil faz-se necessário à medida que se tornam perceptíveis os desafios em compreender e contextualizar os ritmos que se queiram atribuir à ludicidade da criança com limitação visual. Diante disso, pontua-se, ainda, que há a necessidade de reforçar e caracterizar como fundamentais os momentos de interação com outras crianças para que elas tenham a liberdade de explorar de acordo com suas especificidades, tornando-as mais autônomas.

Dessa forma, é preciso que se oportunize o desenvolvimento infantil das crianças com deficiência visuais como quaisquer outras, e que por meio dos jogos, dos brinquedos e das brincadeiras, neste caso das cantigas de roda, a ampliação do trabalho lúdico na perspectiva do convívio social e da educação inclusiva.

\section{CONSIDERAÇÕES FINAIS}

Diante as reflexões com base na revisão de literatura sobre o brincar, da criança com deficiência visual e das minhas experiências profissionais, as vivências para ela são significativas à medida que pais e professores propõem intervenções que potencializem as habilidades dos indivíduos com limitação visual. Diante disso, por meio da ludicidade de 


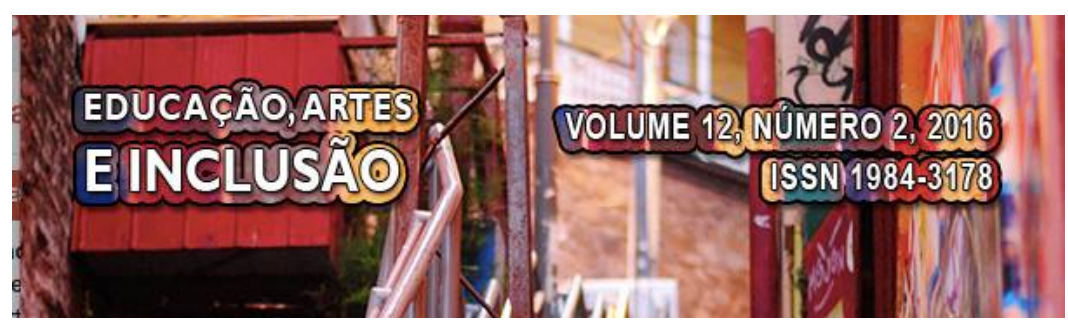

maneira adaptada, a criança é oportunizada às práticas de aprendizagem e considerando o envolvimento com outras crianças.

A criança com deficiência visual quando é exposta às adaptações e ao envolvimento por meio das brincadeiras tem a chance de externar sentimentos, além disso, amplia a construção do conhecimento que se realiza por meio das vivências. $\mathrm{O}$ acesso às brincadeiras, sobretudo, as que se efetivam na coletividade é uma oportunidade indescritível de os professionais da educação trabalhar no fomento das práticas de inclusão, evidenciando o respeito às diferenças, adaptando e readaptando estratégias e, principalmente, enxergar a criança e sua condição de interagir e não apenas enaltecer a deficiência.

A necessidade de permitir a acessibilidade aos momentos lúdicos no contexto da escola inclusiva pressupõe destacar o envolvimento de todos os sujeitos de maneira igualitária. E uma das formas de tornar a acessibilidade uma realidade é organizar com as próprias crianças a confecção de alguns brinquedos artesanais, pois, momentos assim, possibilitam a interação e a valorização e o respeito aos envolvidos.

$\mathrm{Na}$ promoção desses momentos lúdicos destinado ao envolvimento da criança com limitação visual com outras, é importante que os proponentes valorizem a utilização dos sentidos perceptuais e compreender como estes potencializam o processo de aprendizagem, além de auxiliá-las na formulação de conceitos, por isso, as brincadeiras, os jogos e o uso de brinquedos caracterizam as estratégias em um processo de ampliação da linguagem verbal e da expressão corporal.

Elucidou-se a importância da ludicidade na perspectiva da criança invisual, pontuando as possibilidades de interação com outras crianças, tendo base as intervenções de profissionais que acreditem ser agentes promotores de acessibilidade. Foram pontuadas, ainda, as práticas com as cantigas de roda, além disso, algumas sugestões se mostraram pertinentes ao processo reflexivo deste trabalho, enaltecendo, constantemente, as adaptações necessárias.

Destacou-se também a relevância do jogo do faz de conta na concepção da criança como limitação visual que precisa ser valorizado e permitido, entre outras questões, objetivou-se suscitar as discussões que possibilitem o repensar e a oferta de momentos lúdicos destinados ao envolvimento de todos os sujeitos. Dessa forma, almeja-se que os apontamentos reflexivos provocados durante esta abordagem sejam entendidos como pontos norteadores na 


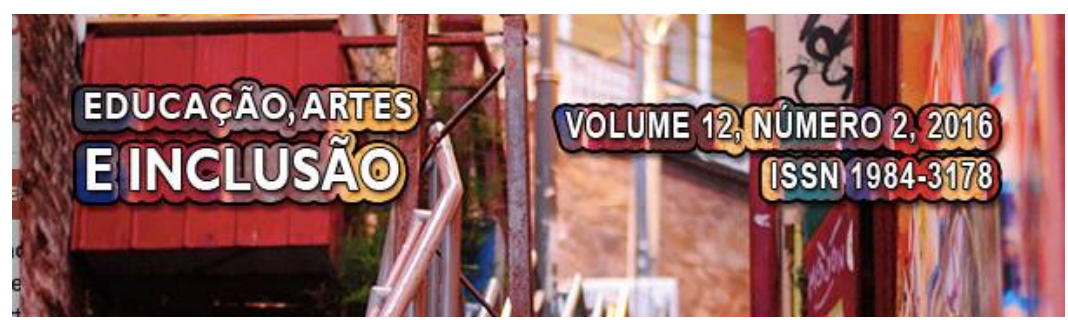

experiência lúdica tanto no contexto escolar quanto no âmbito familiar constituindo-se como práticas de educação inclusiva.

\section{REFERÊNCIAS}

BONDÍA, J. L. Notas Sobre Experiência e o Saber de Experiência. In: Revista Brasileira de Educação, $\mathrm{n}^{\mathrm{o}}$ 19. São Paulo, p. 20 - 28 jan/fev/mar/abr., 2002. Disponível em: $<$ http://www.anped.org.br>. Acesso em 26 out. 2012.

BUENO, E. Jogos e brincadeiras na educação infantil: ensinando de forma lúdica. (Graduação em Pedagogia). Londrina: Universidade Estadual de Londrina, 2010. Disponível em: <http://www.uel.br/ceca/pedagogia/pages/.../ELIZANGELA\%20BUENO.pdf $>$. Acesso em 05 jan. 2013.

DOMINGUES, C. A.; CARVALHO, S. H. R.; ARRUDA, S. M. C. P. Parte I - Alunos com baixa visão. In: DOMINGUES, C. A. [et al]. A Educação Especial na Perspectiva da Inclusão Escolar: os alunos com deficiência visual: baixa visão e cegueira. - Brasília: Ministério da Educação, Secretaria de Educação Especial. Fortaleza: Universidade Federal do Ceará, 2010.

KISHIMOTO, T. M. Jogo, brinquedo, brincadeira e a educação. São Paulo: Cortez, 1999.

MARANGON, C. A garotada entra no ritmo com as danças de roda. In: A Revista do Professor - Nova Escola. Edição Especial: jogos e brincadeiras - 90 sugestões para brincar e aprender. São Paulo: Fundação Victor Civita, 2011.

NEGRINE, A. Aprendizagem e desenvolvimento infantil. Porto Alegre: Propil, 1994.

OLIVEIRA, V. B. (Org.). O brincar e a criança do nascimento aos seis anos. Petrópolis: Vozes, 2008.

ROPOLI, E. A. [et al]. A educação especial na perspectiva da inclusão escolar: a escola comum inclusiva. Brasília: Ministério da Educação/ Secretaria de Educação Especial; [Fortaleza]: Universidade Federal do Ceará, 2010.

SÁ, E. D.; SIMÃO, V. S. Alunos com cegueira (parte II). In: DOMINGUES, C. A. [et al]. A Educação Especial na Perspectiva da Inclusão Escolar: os alunos com deficiência visual: baixa visão e cegueira. - Brasília: Ministério da Educação, Secretaria de Educação Especial. [Fortaleza]: Universidade Federal do Ceará, 2010.

SANTOS, S. M. P. Brinquedo e infância: um guia para pais e educadores. Rio de Janeiro: Vozes, 1999.

SIAULYS, M. O. C. Brincar para todos. Brasília: Ministério da Educação, Secretaria de Educação Especial, 2005. 


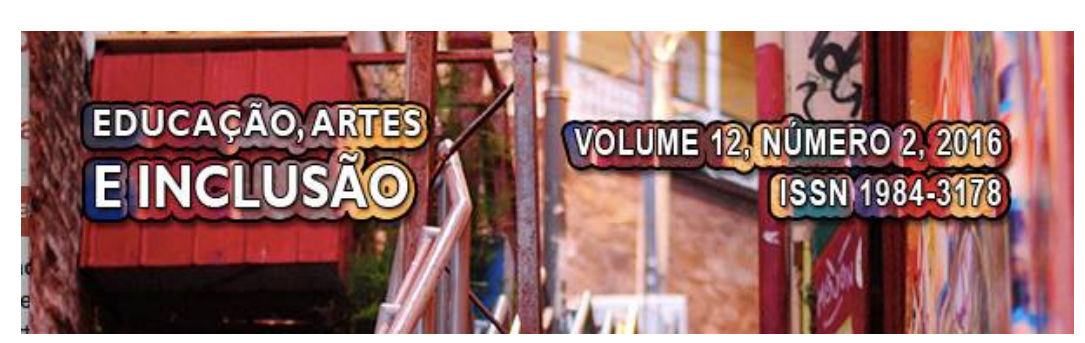

SIAULYS, M. O. C. O papel da família na educação e inclusão das crianças com deficiência visual Laramara: a mudança na prática, na atitude e nas relações com a família. In: MASINI, E. F. S. (Org.). A pessoa com deficiência visual: um livro para educadores. $1^{\text {a }}$ ed. - São Paulo: Vetor, 2007.

VYGOTSKY, L. S. A construção do pensamento e da linguagem. Tradução Paulo Bezerra. São Paulo: Martins Fontes, 2001. 